\title{
Nas entranhas da América: breve análise sobre o cinema de David Lynch \\ Rogério Ferraraz
}

\section{RESUMO}

Este artigo trata dos aspectos do cinema de David Lynch. David Lynch é um cineasta de reconhecida importância no atual quadro da produção audiovisual mundial. Seus filmes, como Eraserhead, Veludo azul, A estrada perdida, entre outros, trabalham com alguns temas recorrentes e apresentam algumas caracteristicas que se repetem, o que permite qualificá-los como traços autorais.

\section{ABSTRACT}

This article deals with David Lynch 's work. David Lynch is recognized as an important director in the current scene of the worldwide audiovisual production. Lynch's movies, as Eraserhead, Bluc Velvet and Lost Highway, work on with some frequent themes and they show some repetitive features, that are features from an author.

\footnotetext{
Rogério Ferraraz é jornalista, mestre em Multimeios pela Unicamp (Campinas/SP) e doutorando em Comunicação e Semiótica pela PUC.SP (São Paulo/SP), onde também participa, como pesquisador, do Centro de Estudos de Cinema (CEC), coordenado pela professora Lúcia Nagib.
} 
Triste sina a nossa, espectadores de cinema no Brasil. Filmes de cineastas como David Cronenberg e Darren Aronofsky eventualmente são exibidos apenas em mostras, obras de Woddy Allen chegam com anos de atraso e por aí vai. Um dos casos mais significativos é o de David Lynch. Não há previsão de estréia do último filme de Lynch nos cinemas brasileiros, mesmo tendo Mulholland Drive proporcionado ao cineasta o prêmio de melhor diretor no Festival de Cannes deste ano (ao lado de Joel Coen, por The Man Who Wasn't There). Dessa forma, a lacuna com a obra lynchiana se abre ainda mais, haja vista que The Straight Story, penúltimo filme de Lynch, lançado internacionalmente em 1999, também não foi exibido em nossas salas e nem comercializado em VHS ou DVD, apesar de ser produzido por um grande estúdio, a Walt Disney, de ter recebido vários prêmios das críticas americana e européia e do ator principal, Richard Farnsworth, ter sido indicado ao Oscar. Esse desinteresse do mercado exibidor brasileiro não diminui o valor da obra de Lynch. Ao contrário, tal fato pode até valorizá-la, se pensarmos na qualidade(?) da maioria dos filmes que dominam nossas telas.

O norte-americano David Lynch é um cineasta de reconhecida importância no atual quadro da produção audiovisual mundial. Ele já foi premiado em Cannes (antes de Mulholland Drive, Lynch levou a Palma de Ouro, em 1990, por Coração selvagem, de 1989), indicado ao 112 Oscar (por O homem elefante, de 1980, e Veludo azul, de 1986), fez trabalhos importantes para a televisão (como a série Twin Peaks, em 1989-90) e também realiza pesquisas de linguagem em filmes desenvolvidos para sites na internet (por exemplo, The Third World, feito para a PlayStation, em 2000). Em função de sua importância e da riqueza que apresenta, a obra de Lynch abre a possibilidade de várias leituras críticas.

Lynch é um cineasta contemporâneo ainda sem um nicho histórico específico, o que permite ao analista de sua obra explorar um campo novo e fértil de sigrificados: Seu cinema opera com alguns temas recorrentes e traz algumas características que se repetem, o que permite qualificá-los como traços autorais, sendo que vários deles são apropriações e releituras de filmes de outros cineastas ou de vários gêneros, como a ficção científica, o film noir, o road movie, o filme de horror, sempre utilizando os principais clichês desses gêneros para subvertêlos. Há também em seus filmes, ecos de vários momentos e escolas da história do cinema, bem como de aspectos plásticos e literários de artistas diversos.

Como num jogo de quebra-cabeças, seus filmes tanto exploram as convenções narrativas quanto realizam uma renovação da linguagem 
cinematográfica, embaralhando procedimentos ilusionistas $e$ antiilusionistas. Lynch desenvolve uma espécie de hiper-realismo cinematográfico, como que traduzindo para a película a beleza enigmática das cores e das luzes da pintura de Edward Hopper, e constitui, assim, um cinema limítrofe, baseado nos contrastes e nas analogias entre ilusão e realidade, sanidade e loucura, mundo interior e mundo exterior, universo adulto e universo infantil.

Ismail Xavier, em 1984, apontava que, no cinema atual.

a citação, o refazer, o deslocar (...) passam a primeiro plano, novamente. (...) E a tônica da produção autoral é uma 'ficção de segundo grau', a repetição de dispositivos clássicos que se julga (e esperemos que sim) ganhar novo sentido porque sua atmosfera não é mais a de um uso inocente da convenção e do repertório mas a do rearranjo hiperconsciente das mesmas figuras de estilo, deslocadas. revigoradas pela introdução de ingredientes novos. A grande aposta é que, em todc este processo de reiterações e deslocamentos, o cinema de hoje faça ver melhor as próprias convenções de linguagem. a.s leis dos gêneros da indistria cinematográfica e seu sentido, ideológico e político, no interior da cultura de massas. ${ }^{1}$

Ao misturar, de forma consciente e criativa, estilos, formas $e$ temas de diversos momentos, escolas e gêneros do cinema, Lynch é um dos poucos ciileastas norte-americanos que confirmam essa "grande aposta" e com isso provoca, retomando o conceito freudiano do wheimlich, o estranhamento no espectador.

O próprio Lynch percebe esse amálgamal estético em suas obras. Em A estrada perdida, cujo roteiro foi feito em parceria com Barry Gifford, autor do romance que deu origem também a Coração schat gem, ele desenvolve ainda mais seu quebra-cabeças de imagens o sons, em que il esquizofrenia e o duplo são fatores imprescindiveis. Pelas palavras de Lynch, A estrada perdida representa:

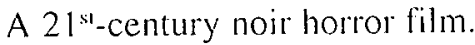

A graphic investigation into parallel identity crises.

A world where time is dangerously out of control.

A terrifying, ride down the lost highway. ${ }^{2}$

Assim, Lynch, mais uma vez, nos faz pensar em momentos e gêneros distintos da história do cinema, como o filme noir. o expressionismo alemão e o surrealismo. Do filme noir. temos, por exemplo, a utilização dos recursos do romance policial e do suspense. 
Ligadas ao expressionismo, encontramos a questão do duplo e personagens que transitam entre os limites da normalidade e da loucura, geralmente inclinadas a algum tipo de psicopatia. O mais importante aqui, no entanto, é a relação existente com o surrealismo. Os universos distintos que sa mesclam, o jogo com o tempo, a figura da mulher, neste caso, duplicada, nos fazendo lembrar, por exemplo, da personagem Conchita de Esse obscuro objeto do desejo (1977), de Buñuel, são apenas alguns aspectos facilmente observáveis em $A$ estrada perdida.

Guillermo Cabrera Infante também percebe essas marcas no cinema lynchiano, ao afirmar que, na obra do cineasta:

El aura surreal (Dali, Ernst, Magritte) es una claridad atroz. En la atmosfera expresionista (Lang, Siodmak, Hitchcock) hay un predominio del claroscuro (...) Dali (...) es el maestro más remoto, terremoto (...) Lynch en Eraserhead es más Dali que Buñuel, pero en sus películas posteriores hay algo del eros de Buñuel... ${ }^{3}$

Alguns dados biográficos talvez sirvam para compreendermos os aspectos distintos e até díspares de sua arte. David Lynch nasceu em 1946, em Missoula, no estado de Montana. Filho de um engenheiro florestal que trabalhava para o governo, Lynch acompanhava o pai 114 em expedições por florestas e matagais, o que, talvez, explique sua obsessão por tais lugares em seus filmes. Com seus pais, ele viajou por todo interior dos Estados Unidos e passou sua infância em várias cidades e estradas, um verdadeiro nômade em plenos anos 50 . Ao atingir a maioridade, Lynch tornou-se batedor de polícia. Nessa profissãó "ele não permaneceria por muito tempo. Já nesse período, o jovem Lynch sentia-se atraído pelo mundo fascinante e lúdico das artes.

Frequientou a escola de arte do Boston Museum, mas desistiu do curso e foi para a Europa. O que seria uma longa aventura tornou-se uma breve viagem de dez dias. De volta aos Estados Unidos, o irrequieto espírito "nômade" de Lynch não permitiu que ele parasse por múito tempo em nenhum emprego. Ele demonstrava uma constante insatisfação com a ordem do cotidiano. Lynch mudou-se, então, com sua primeira mulher, para a Filadélfia, lugar que o marcou profundamente. Para o cineasta, Filadélfia é "a cidade mais nojenta" que ele já conheceu. Uma das razões para esse sentimento de repugnância pode estar ligada ao fato do casal ser vizinho do necrotério local.

Ainda na Filadélfia, Lynch e sua mulher estudaram na Academia de Belas-Artes. Mas, com a separação do casal, ele foi para Los Angeles. Nessa época, Lynch já havia realizado dois curtas-metragem 
independentes: Six Figures or Six Men Getting Sick (1966) e The Alphabet (1968), este escrito por ele a partir da descrição de um sonho de uma garota de seis anos, sobrinha de uma amiga de Lynch. E foi assim que ele obteve uma bolsa no American Film Institute. No AFI, Lynch fez, ainda em 1968, junto com Frederick Elmes (fotógrafo e futuro parceiro de Lynch em vários filmes), o curta The Amputee e rodou, em 1970, o curta de animação The Grandmother. Com esse filme, o cineasta conseguiu entrar para o Centro de Estudos Avançados de Cinema de Los Angeles. Em 1972, com 20.000 dólares conseguidos novamente no AFI, ele iniciou a realização de seu primeiro longa-metragem. Eraserhead demorou 5 anos para ser concluído, sendo lançado em 1977 e logo tornando-se objeto de culto.

A partir daí, com filmes como os citados $O$ homem elefante, Veludo azul, Coração selvagem e The Straight Story, além de Duna (1984), Twin Peaks - Os últimos dias de Laura Palmer (1992) e A estrada perdida (1997), só para mencionarmos os longas por ele dirigidos (incluindo agora Mulholland Dive), Lynch passa a ser reconhecido como um dos cineastas mais criativos e instigadores do cinema atual. Suas obras apresentam certos temas e características recorrentes, que tentamos observar nos três tópicos a seguir.

\section{A questão espaço-temporal, o movimento circular e a crise das aparências}

Ao contrário da narrativa clássica, em alguns filmes de Lynch, o esquema de início, meio e fïm definidos é subvertido. Eraserhead é repleto de passagens que contrariam a lógica das coisas, com saltos no tempo e no espaço, que, na verdade, nem se apresentan como saltos, pois a própria lógica de tempo e espaço encontra-se modificada pelas ações das personagens. Elas não pertencem a nenhum tempo e espaço demarcados, retomando características do cinema surrealista, especialmente de Um cão andaluz, feito, em 1928, pelos espanhóis Luis Buñuel e Salvador Dalí, como a não-continuidade espaço-temporal, o uso de elipses, a não-linearidade cronológica. Em A estrada perdida, a frase que abre a história é a mesma que a encerra, mas se, no início, é Fred Madison (Bill Pullman) quem a ouve pelo interfone de sua casa, no fim, é ele mesmo quem a diz, como se o final do filme voltasse ao ponto de partida da história narrada. Tal cena confirma a circularidade da narrativa, indicada em vários momentos da obra.

Aliás, a idéia de circularidade temporal vem acompanhada pelo movimento circular da câmera. O círculo é uma constante nos fílmes de Lynch, seja no desenvolvimento da narrativa seja na abordagem 
temática. A câmera que circula e "penetra" a orelha decepada no início de Veludo azul é uma amostra desse recurso. O trabalho com o movimento circular, retomando idéias de. Kracauer ao analisar o cinema alemão do período entre guerras, remete ao universo dos circos e dos parques de diversão, justamente porque estes lugares não obedeciam às regras culturais e rígidas do jogo social burguês, pois eram fundados na idéia de círculo, portanto, de caos, e tinham, assim, uma função anárquica. Por isso, representavam um lado revolucionário, transformador. Uma relação semelhante pode ser vista em $O$ homem elefante, por exemplo. Em Veludo azul, esse movimento circular, além de indicar realidades concomitantes de um mundo específico (a cidade de Lumberton), remete também ao universo psíquico-subjetivo do próprio protagonista. Apesar de se configurar a partir de um procedimento diferente, tal relação entre movimento circular e universo psíquico-subjetivo faz lembrar a estrutura desenvolvida por Fritz Lang em $M$, partindo da idéia de circularidade do leitmotif, em que a música assobiada pelo assassino nos remetia ao seu processo crescente de esquizofrenia. Vale lembrar que a crítica Pauline Kael também encontra semelhanças entre as ruas em que o personagem de Peter Lorre caminhava em $M$ e os locais percorridos pelo protagonista Henry (interpretado por Jack Nance) em Eraserhead. ${ }^{4}$

116 Em Veludo azul, ocorre um processo diferente de estranhamento relativo ao tempo e espaço. Se, por um lado, há uma história que segue uma progressão temporal, em que há início, meio e fim, como numa narrativa clássica tradicional, por outro, há um confronto entre a história que é contada e a ambientação (imagética e sonora) dessa história. A cidade de Lumberton parece ter parado na década de 50 , apesar da história ser atual. Assim, Lynch expõe uma das facetas da arte pós-moderna, a confusão e a mistura de diversos universos artísticos e estilísticos de épocas distintas. Essa confusão temporal observada em Veludo azul, além de refletir uma marca do cinema atual, recupera também uma das características da estética surrealista, a beleza convulsiva, resultante do encontro de realidades distintas (às vezes, contraditórias) num mesmo espaço e tempo. Facilmente observável nas pinturas surrealistas, a beleza convulsiva também aparece em alguns filmes, como, por exemplo, em Simão do deserto, de Buñuel, quando, no meio da história, que parece ocorrer no século $\mathrm{V}$, um avião (chamado de "jato na contramão" por Eduardo Peñuela Cañizal) aparece e faz sumir o protagonista, levando-o para uma discoteca de Greenwich Village do século XX. Esse encontro de elementos totalmente distintos e conflituosos, que se configura como a bele- 
za convulsiva dos surrealistas, na qual há, por vezes, um embaralhamento de sinais e icones de épocas diversas, também acontece nas obras de Lynch.

Para atingir e compreender a força dessa beleza convulsiva. é preciso libertar o olhar domesticado. Em Um cão andaluz, nos deparamos desde o início com o jogo entre imagens díspares. A navalha rasgando o otho da mulher e a nuvem passando na frente da Lua. em montagem paralela, já demonstra que o fillme não será pautado pelo olhar e pela arte tradicionais. O sentimento estranho causado pelas imagens pode tornar-se ainda mais enigmático pelo jogo metafórico ali presente. Podemos ver nessa montagem inicial uma construção discursiva em que o sentido literal de certos objetos ou ações é desiocado. A navalha rasgando o olho diz muito mais a respejto da pulsão sexual do que, apenas, do próprio ato de cortar o globo ocular. Aliás, essa conotação era perceptível também na literatura surrealista, através da obra de Georges Batailles. Em $A$ história do olho, dois jovens amantes praticam todos os tipos de jogos sexuais a fim de atingirem um gozo pleno. Numa determinada passagem, acompanhados de um senhor mais velho. eles forçam um padre a fazer sexo com a garota, que o mata, estrangulando-o. Ela pede ao senhor que os acompanha para retirar um dos olhos do padre, com o qual se masturbará a seguir.

A cena de Um cão andaluz, além desse teor sexual, nos coloca diante de uma das preocupações surrealistas, a de enxergar além dessa realidade aparente. $O$ corte do olho permite que a realidade das coisas, que o mundo sejam percebidos através de uma nova visão. Uma visão livre das regras sociais, livre dos véus que hipocritamente cobrem e escondem facetas diversas do homem e da sociedade.

Véus que transformam-se em veludo azul, na ótica de David Lynch. Assim como Buñuel, o norte-americano também alcança a beleza convulsiva ao nos mostrar um mundo escondido, que os olhos mais burocráticos e sedados não percebem. No início de Veludo azul, Lynch também trabalha com elementos distintos: o veludo azul que se funde com o céu, as cores tradicionais da bandeira norte-americana no plano que enquadra o céu, a cerca e as flores, a música alegre, a felicidade que parece reinar na pequena cidade. um homem regando seu jardim; e, de repente, após um enfarte e a queda brusca daquele homem, a câmera seguindo a água que jorra da mangueira e penetrando no solo, mostrando insetos que devoram a terra, numa seqüência de lons escuros e sons perturbadores.

Esse início também nos coloca algumas idéias a respeito da própria obra, bem como da visão de seu cineasta. $O$ mergulho que a 
câmera faz para dentro da terra, mostrando o que nossos olhos não podem ver, ou não querem ver, é a mesma que vai acompanhar o jovem Jeffrey (Kyle MacLachlan) em sua descida ao inferno de Lumberton. Lynch nos dá logo no início as pistas para entendermos sua obra: ele não se contentará em mostrar essa realidade a que nos acostumamos; sua lente se abrirá para o que está por baixo, por trás, pelos lados dessa pretensa feliz realidade, independente se essa abertura trará aspectos muitas vezes desagradáveis aos espectadores. $\mathrm{Na}$ verdade, ele quer mesmo mostrar esse lado perverso, violento, "desagradável" do ser humano, e o quanto isso está ligado ao instinto, ao desejo.

David Lynch também expõe o caráter dos homens de viver sob um manto de aparências e ilusão. $O$ homem elefante ${ }^{6}$ traz a história, passada na Londres de 1884, de um cirurgião que compra, de uma espécie de circo de horrores, um ser humano todo deformado, que passa a ser explorado pelo médico, sob a bandeira da curiosidade científica, até que uma atriz faz dele seu protegido.

A fotografia em preto-e-branco é um dos pontos altos do filme, que reproduz a Londres vitoriana, causando um efeito de mistério e acentuando a carga dramática. A figura do homem elefante, encapuzado, tentando manter contato com as pessoas ou pelo menos ser compreendido a não ser alvo da curiosidade e da ganância huma-

118 na, nos remete para um dos quadros emblemáticos do belga René Magritte, Os amantes. A obra de 1928, que traz duas pessoas também encapuzadas pelo véu que encobre a paixão, o desejo, reflete uma das preocupações de Magritte: mostrar que o homem precisa enxergar através do véu que oculta as verdades da realidade das coisas e do mundo. Se aqui a paixão está no centro das preocupações, em $O$ homem elefante, Lynch mostra que, por trás do pano que cobre um rosto deformado por uma terrível doença, encontra-se um oásis de bondade e delicadeza, ao contrário de muitos humanos considerados normais, mas que escondem-se atrás das máscaras da hipocrisia, das aparências, do jogo social.

Em Coração selvagem, Lynch mais uma vez ironiza esse culto das aparências' numa cena marcada também pela construção surrealista: o casal Sailor e Lula, vividos por Nicolas Cage e Laura Dern respectivamente, pára com seu carro ao ver um acidente; aparece, então, uma moça (interpretada por Sherilyn Fenn), toda sangrando, que está preocupada em achar seu pente, para poder se arrumar e (a)parecer bonita para os outros.

\section{A questão do espelho e a mistura de mundos distintos}


Lynch trabalha as relações entre sonho e realidade, entre o ato de dormir e $o$ ato de despertar de maneira a causar uma inquietante estranheza. Em Eraserhead, muitas vezes, quando o protagonista acorda, a sequência, que seria a representação de um sonho, continua. Esse tipo de construção ocorre em vários filmes de Lynch, que dialoga, dessa forma, com o tratamento dado ao sonho no cinema fantástico e, principalmente, no surrealista. No cinema de Lynch, sonho e realidade se relacionam, se cruzam e se fundem. Os espaços de demarcação são abolidos. não há limites precisos entre o real e o onírico, que aparecem entrelaçados. Na série Twin Péaks, o caso da morte de Laura Palmer (Sheryl Lee) é, de fato, resolvido num sonho do agente Dale Cooper (Kyle MacLachlan).

Eraserhead, Os áltimos dias de Laura Palmer e A estrada perdida também trazem marcas do realismo poético, dialogando. por exemplo, com Sangue de um poeta, dirigido por Jean Cocteau, em 1930. Esta obra trazia as inquietações do artista-poeta frente às (im)possibilidades criadoras e criativas. Apesar de algumas características o ligarem ao surrealismo, como as imagens oníricas, as visões provocativas, as representações do inconsciente, o filme, na verdade, relaciona-se mais com o realismo poético. Fator marcante da obra é a intensa preocupação subjetiva do artista em detrimento às discussões sociais e políticas. A questão do espelho em que o artista mergulha, numa viagem para dentro de sua mente e de sua alma, é retomada nesses filmes de Lynch, em que corredores, portas e, claro, espelhos levam personagens e espectadores a lugares estranhos e primitivos, que podem ser vistos como passagens para o interior do inconsciente humano e também como representação da inter-relação entre dois mundos, o dos vivos e o dos mortos.

Os surrealistas também gostavam de tratar do objeto espelho na tentativa de questionar os limites da reprodução e do reflexo, do que era material e do que era imaterial. Um dos quadros mais famosos de Magritte, por exemplo, A reprodução interdita (retrato de Edward James), de 1937, traz a figura de um homem que se olha no espelho e a imagem refletida é a mesma de quem o olhal por trás, ou seja, no espelho, a figura também está de costas, contrariando a lógica tradicional (o estranhamento é ainda mais significativo porque Magritte pintou um livro - Aventuras de Arthur Gordon Pym, de Edgar Alan Poe - sobre o balcão com o reflexo "normal" no espelho). Essa figura, com terno e penteado impecáveis (presente em outras obras do pintor belga), é bem semelhante ao agente Dale Cooper, criado por Lynch para Twin Peaks. Uma cena chave em Os últimos dias de Laura Palmer retoma algumas questões presentes no quadro de Magritte, 
mas agora, em vez de um espelho, há um circuito interno de vídeo, no prédio do FBI, na Filadélfia. Cooper olha para a câmera de vigilância num corredor e entra numa sala para ver o que aquela câmera registra. Na terceira vez em que faz isso, ele vê sua imagem congelada no monitor e o agente Phillip Jeffries, personagem de David Bowie, passar ao lado dela, numa seqüência que, da mesma forma que o espelho de Magritte, também contraria a lógica tradicional e atualiza e presentifica na diegese um personagem que provavelmente encontra-se morto.

Essa sequiência desencadeia um processo de reflexão sobre o próprio filme, numa espécie de metacinema, numa construção que denuncia a ilusão de realidade fabricada pelo meio. Essa relação de imagem dentro da imagem também volta em $A$ estrada perdida $\mathrm{e}$ parece ser uma preocupação de alguns cineastas atuais, como mostra Wim Wenders e seu $O$ fim da violência, por exemplo. Na seqüência de Os últimos dias de Laura Palmer, há um processo de presentificação daquele fato, daquela imagem. Lynch parece brincar com os conceitos de realidade e cópia, de materialidade e imaterialidade, de corpo e espírito nessa sequêencia, nos colocando, espectadores, no meio de um jogo, em que tentamos juntar cacos e peças para completar a história, como num quebra-cabeça. Mesmo jogo, aliás, desenvolvido em Eraserhead, Veludo azul e A estrada perdida.

Assim como a Alice, de Lewis Carrol, que se aventura através do espelho, os personagens de Lynch parecem habitar dois mundos distintos, mas que - e aqui se encontra o sentido de encantamento e de horror em sua obra - fazem parte de uma mesma realidade. Ao lembrar da personagem de Carrol, nos deparamos com outra característica freqüiente nos filmes de Lynch: a presença do mundo infantil através de imagens, sons, lembranças. Reminiscências de uma época que aparece maculada pelos desejos e culpas do mundo adulto, sentimento que parece saltar dos olhos de Pete Dayton (Balthazar Getty) ao observar, por cima da cerca de sua casa, uma piscina de plástico e um barquinho de brinquedo, enquanto ouvimos os acordes de Insensatez, de Tom Jobim, em A estrada perdida. As personagens lynchianas são seres "sem rumo", que rapidamente locomovem-se pelas estradas perdidas, mergulhando dentro de suas dúvidas, de suas buscas pelo prazer mais íntimo.

Observa-se uma preocupação maior em mostrar os dilemas psicológicos do homem perdido em meio ao caos urbano e às descobertas do mundo adulto. Com seus filmes, Lynch procura penetrar nas entranhas do ser humano e investigar os subterrâneos da sociedade norte- 
americana através do desnudamento dos sentimentos, das angústias e dos medos. No mesmo ato em que desvenda cada personagem individualmente, ele ergue o véu da aparente felicidade que encobre a sociedade americana. Esse jogo entre individual e social é trabalhado de forma paralela e análoga à maneira com que a câmera habita e percorre ambientes fechados e abertos, o interior e o exterior, o que se reflete, por sua vez, no embate entre claro e escuro. Mas, quebrando a visão dicotômica de separação entre mundos interno e externo, entre maldade e bondade, entre loucura e sanidade, suas obras embaralham o sentido das coisas para mostrar a complexidade do ser humano mergulhado no mundo, um mundo misturado e caótico.

\section{A questão do grotesco e dos contrastes e a ironia antiilusionista}

Outra característica do cinema de Lynch, que aparece também nas obras de alguns cineastas atuais como David Cronenberg, por exemplo, é a presença de elementos bizarros, que tendem ao grotesco, como partes decepadas do corpo humano, pessoas com deformações, enfermos, cegos, anões, enfim, elementos que escapam do dito padrão tradicional e até mesmo o enfrentam.

Jean-Claude Bernardet, ao analisar o curta Noite final menos cinco minutos, de Débora Waldman, relacionando-o à obras de Paulo Sacramento e Fernando Bonassi. constata uma característica do cinema dos anos 90: a "crueldade irônica" 7 . Apesar de notar uma particularidade brasileira na questão, Bernardet deixa claro que não se trata de um aspecto apenas de nosso cinema, como mostra ao citar o caso de Cães de aluguel, de Quentin Tarantino. É possivel enxergar os traços dessa crueldade irônica também nos filmes de Lynch (como nos de Cronenberg), porém, creio que, neste caso, a preocupação que move o cineasta seja de outra natureza.

Pode-se relacionar essa marca do cinema lynchiano com vários momentos, estilos e gêneros da história do cinema, até mesmo com o chamado primeiro cinema e sua relação com os circos, feiras e raudevilles do final do século XIX e início do século XX, e também com o cinema de horror e ficção das décadas de 30 e 40 , realizado pelos grandes estúdios (especialmente a Universal), do qual pode-se citar o clássico Freaks, de Tod Browning, feito em 1932, que encontra eco em várias obras de Lynch, desde Eraserhead até Twin Peaks, passando, claro, por $O$ homem elefante. É possível, também, traçar um paralelo entre a forma de abordagem dos surrealistas e a de Lynch sobre o tema, não só nos filmes como também nas obras fotográficas 
e plásticas. Os surrealistas tinham obsessão pelo desmembramento de partes do corpo, ou pelo seu corte, com algum objeto rasgando a carne humana. Essa característica pode ser observada nas fotografias de Man Ray, nas telas e esculturas de Dalí e Magritte, na literatura de Bataille, por exemplo. No cinema, basta lembrar da abertura de Um cão andaluz ou, então, da perna amputada de Catherine Deneuve em Tristana, para ficar em apenas dois exemplos famosos. Nos filmes de Lynch, bem como em seus quadros e fotografias, essa obsessão retorna com muita força, como se vê na comentada cena da orelha em Veludo azul, na mão decepada que é carregada por um cachorro e na cabeça arrancada de Bobby Peru (Willem Dafoe) em Coração selvagem ou na cabeça que se desprende do corpo do protagonista e quie serve para fabricar borrachas para lápis em Eraserhead, na seqüência onírica mais intrigante do filme. Além disso, Lynch também focaliza figuras que fogem do chamado padrão normal, tais como os anões, os gigantes, os cegos, os deformados e os aleijados. Basta citar o anão e o homem sem braço em Os últimos dias de Laura Palmer, o bebê monstruoso e os seres deformados de Eraserhead ou o próprio homem elefante da obra homônima.

O happy ending, uma das marcas do chamado cinema comercial ou convencional, também acontece com freqüência em filmes de 122 Lynch, mas não da maneira como funciona para as comédias românticas ou para as fitas de ação feitas por Hollywood. A ironia é o que prevalece aqui. Vale dizer que, nas obras de Lynch, várias vezes o espectador se depara com histórias de amor, com enredos sobre relacionamentos humanos. Mas, ao contrário da maioria dos filmes sobre casais apaixonados, em que o encontro carnal mal acontece e a estética lacrimogênea se sobressai, nos filmes de Lynch, o amor é acompanhado do prazer físico, do orgasmo, sempre próximo dos elementos escatológicos, numa arte em que o gozo e o excremento parecem estar sempre em comunhão, como na plástica de Dalí ou na literatura de Sade ou de Bataille.

A forma de interpretar dos atores também é uma marca diferencial do cinema de Lynch. Observando como Jack Nance faz o protagonista Henry, em Eraserhead, nota-se que Lynch dirigiu o elenco para que fugisse do modelo de representação naturalista, tão cara ao cinema narrativo clássico. $O$ jeito de andar de Henry lembra a forma com que os atores dos primeiros filmes caminhavam. Mas, se naqueles, o efeito era obtido pela captação e reprodução das imagens, em Eraserhead, é a própria expressão corporal do ator que provoca tal efeito. Não se trata de um caminhar normal. As ações e falas dos per- 
sonagens também são incomuns, longe dos padrões convencionais. À primeira vista. poderíamos classificá-los como loucos, doentes, mas não é bem assim. Na diegese do filme, essas ações e falas são perfeitamente cabíveis. os personagens não sofrem julgamentos morais por parte do narrador. Eles são o que são. Outra característica é a interpretação marcadamente caricata dos atores, como em Veludo azul, Coração selvagem e A estrada perdida, evidenciando que se trata apenas de uma representação de certa personagem, desnudando, assim. seu universo ficcional, o que está longe. mais uma vez, do estilo naturalista de interpretação. Esse caráter oposto ao naturalismo é uma das peças antiilusionistas utilizadas por Lynch, mas que também se afasta um pouco das propostas de Brecht e suas técnicas de distanciamento, que tanto influenciaram os Cinemas Novos pelo mundo. O cineasta, por exemplo, dificilmente volta sua câmera para o espectador, não se dirige a ele, o que é uma das táticas mais utilizadas por diretores que querem desmascarar o ilusionismo cinematográfico. Lynch não faz uso desse recurso, a não ser raramente, como no início de Veludo az,ul, quando um bombeiro acena em direção à câmera num momento em que nada indica que aquela era uma câmera subjetiva. Ou seja, nesse breve instante que contrasta com o resto da narrativa, temos a sensação de que o aceno foi feito para nós, espectadores, como se para nos chamar a atenção à história incomum que irá se desenrolar.

O modo de tratar o som também passa pelo fascínio que Lynch tem pelos contrastes e pelas contradições. (Vale dizer que Lynch geralmente é o responsável pela edição de som de seus filmes, além de trabalhar junto com Angelo Badalamenti. seu habitual colaborador, na concepção da tritha sonora) Ele trabalha sempre com contrastes e contrapontos sonoros e imagéticos. Em Veludo azul, monta um complexo jogo entre som diegético e extradiegético para reforçar os contrastes do filme. Além disso, a música nem sempre corresponde à atmosfera da ação, o que a música transmite e o que se passa nas imagens são visões e sensações opostas, até mesmo contraditórias. A música e o som não servem apenas para confirmar o que as imagens já mostram, muitas vezes, podem vir a negar ou a se contrapor a elas. contrariando as regras do cinema ilusionista.

Um exemplo dos contrastes trabalhados no som, bem como no uso extremado das cores, que faz lembrar o hiper-realismo dos quadros de Hopper (uma referência presente também nos filmes de Wim Wenders), pode ser visto na sequiência em que o pai do protagonista Jeffrey tem um enfarte no início de Veludo azul. Ele está regando seu jardim, a música alegre toca no rádio. as cores são vivas, tudo está 
calmo. Ele, então, sofre o enfarte. Cai. A água continua jorrando da mangueira. A música vai diminuindo e estranhos sons são amplificados. A câmera acompanha a água e, lentamente, vai descendo pela terra, onde os insetos se movimentam freneticamente. Os ruídos dos insetos transformam-se em acentos musicais. Essa técnica realça a tensão da cena, instaurando o universo do horror e do grotesco. Do mesmo jeito que os insetos estão devorando a terra, numa sequiência de tons escuros, contrastando com as imagens anteriores, que mostravam os tons claros das cores vivas das flores, das casas, das roupas, os acentos musicais que realçam a ação dos insetos contrastam com a música anterior, bem pop, estilo anos 50 .

Aliás, os anos 50 são uma verdadeira mania para David Lynch. Veludo azul, por ex̧emplo, se passa no tempo presente, mas os personagens, a música, a cenografia, enfim, tudo parece ter saído diretamente da década de 50. Essa mania não é negada por ele, como mostra nessa entrevista a Ana Maria Bahiana:

Sou louco pelos anos 50 e tudo o que se refere aos anos 50. Mas, para mim, quando eu me refiro aos anos 50 , tanto em imagem quanto em som, estou me referindo na verdade a uma lembrança dos anos 50 (...) Uma coisa nostálgica. ${ }^{8}$

124 A nostalgia é uma das marcas da cultura pós-moderna, como observaram Fredric Jameson, Andreas Huyssen e outros. De acordo com Jameson ${ }^{9}$, o pós-moderno é um campo de forças onde impulsos residuais e emergentes encontram seus caminhos, sendo que os artistas trabalham corr. estruturas esquizofrênicas. Essa esquizofrenia a que Jameson se refere diz respeito ao total embaralhamento das idéias e dos momentos estéticos históricos. A análise que ele faz da arquitetura é referencial. Porém, acredito que Jameson é um tanto quanto inflexível em relação às não qualidades das obras pós-modernas, no que se refere ao cinema; inclusive. A análise que ele faz da utilização da paródia e do pastiche caminha nessa direção. Para ele, a arte contemporânea caracteriza-se frequientemente pelo pastiche, que vem a ser uma canibalização de vários estilos feita de maneira aleatória, totalmente acrítica. Temos que ter atenção redobrada, portanto, para verificar quando está presente este pastiche "vazio" e diferenciá-lo da paródia e do uso consciente das citações. Se considerarmos, por exemplo, filmes como Coração selvagem e $A$ estrada perdida, torna-se claro que o jogo com as citações e com a paródia é feito de maneira crítica e madura, em que a ironia serve até como mecanismo antiilusionista. 
Como já ficou evidente, nos distanciamos em alguns pontos do essencial texto de Jameson. Dessa forma, nossa análise aproxima-se mais dos estudos de Andreas Huyssen - que reserva críticas veladas a Jameson - sobre o pós-moderno ${ }^{10}$, principalmente quando ele trata da questão da nostalgia pós-moderna. Se, para Jameson, isso representava um decadente índice de criatividade do capitalismo tardio, para Huyssen ela pode demonstrar um alto grau de insatisfação com os rumos da modernidade.

De qualquer forma, num ponto todos se aproximam: o pós-moderno se caracteriza por um ecletismo muito grande de estilos, de formas, de paradigmas. Portanto, falar em estética pós-moderna é uniformizar um pluralismo de possibilidades artísticas, das quais o cinema de David Lynch representa apenas uma rica e fértil opção.

\section{Notas}

1 XAVIER, Ismail. O discurso cinematográfico. Rio de Janeiro: Paz e Terra, 1984. p. 146s.

2 LYNCH, David \& GIFFORD. Barry. Lost Highway. London/ Boston, 1997, p. 5.

3 INFANTE, Guillermo Cabrera. "Para entender a David Lynch Un Faulkner para los '90". In: Primer Plano. 06/ 10/91, p.3.

4 KAEL, Pauline. 1001 noites no cinema. São Paulo: Companhia das Letras, 1994. p. 165.

5 Nem sempre Bataille é reconhecido como exemplo de escritor surrealista. Aqui, seguimos o pensamento de Alexandrian, que o coloca dentro dessa classificação. Ver em ALEXANDRIAN, Sarane. História da Literatura Erótica. Rio de Janeiro, Rocco, 1996, p. 381-437.

60 homem elefante é baseado na história verídica sobre a vida de John Merrick, um cidadão inglês que sofria de uma doença chamada neurofribromatose aguda, causadora de terriveis deformações. O filme foi baseado nos livros The Elephant Man and Other Reminiscences, de Sir. Frederick Treves (o médico que cuida de Merrick), e em The Elephant Man: A Study in Human Dignity, de Ashley Montagu.

7 BERNARDET, Jean-Claude. «A crueldade irônica». In: Revista Imagens - no. 02. Campinas, Uicamp, 1994 . p. 40-43.

8 BAHIANA, Ana Maria. A luz da lente. São Paulo, Globo, 1996, p. 42. 
9 JAMESON, Fredric. Pós-Modernismo. São Paulo, Ática, 1996.

10 HUYSSEN, Andreas. Mapeando o Pós-moderno. Rio de Janeiro, Rocco, 1991.

\section{Bibliografia}

ALEXANDRIAN, Sarane. O surrealismo. Trad. de Adelaide Penha Costa. São Paulo: Verbo/EDUSP, 1976.

Trad. de Ana Maria Scherer \& José Laurênio de Mello. Rio de Janeiro: Rocco, 1994.

ATKINSON, Michael. Blue Velvet. London: British Film Institute, 1997.

BAHIANA, Ana Maria. "David Lynch". In: A Luz da Lente: conversas com 12 cineastas contemporâneos. São Paulo: Globo, 1996. p. 39-47.

BATAILLE, Georges. História do olho. Trad. de Glória Correia Ramos. São Paulo: Escrita, 1981.

BERNARDET, Jean-Claude. «A crueldade irônica». In: Revista Imagens - no. 02. Campinas, Uicamp, 1994 , p. 40-43.

BORDWELL, David; STAIGER, Janet; THOMPSON, Kristin. The Classical Hollywood Cinema: Film Style \& Mode of Production to 1960. New York: Columbia University.

BRESKIN, David. "David Lynch". In: Inner Views: Filmmakers in Conversation. New York: Da Capo, 1997. p. 51-95.

BRETON, André. Manifestos do Surrealismo. Trad de Luiz Forbes. São Paulo: Brasiliense, 1985. Editorial Estampa, 1971.

BUÑUEL, Luis. Meu último suspiro. Trad. de Rita Braga. Rio de Janeiro: Nova Fronteira, 1982.

CARROL, Lewis. Aventuras de Alice. Trad. e Org. de Sebastião Uchôa Leite. 3.ed. São Paulo: Summus, 1980.

CHION, Michel . David Lynch. Trad. de Robert Julian. Londres: British Film Institute, 1995. 
CORRIGAN, Timothy. A Cinema Without Walls: movies and culture after Vietnam. New Jersey: Rutgers University Press, 1991.

COSTA, Flávia Cesarino. O primeiro cinema: espetáculo, narração, domesticação. São Paulo: Scritta, 1995.

FERRARAZ, Rogério. O veludo selvagem de David Lynch: a estética contemporânea do surrealismo no cimema ou o cinema neo-surrealista. Dissertação (Mestrado em Multimeios). Campinas, SP: Unicamp, 1998.

FREUD, Sigmund. "O estranho". In: Obras psicológicas completas de Sigmund Freud (Vol. XVII). Rio de Janeiro: Imago, 1996.

HOFFMANN, E. T. A . Contos fantásticos. São Paulo: Melhoramentos, $\mathrm{s} / \mathrm{d}$.

HUYSSEN, Andreas. "Mapeando o pós-moderno". In: HOLLANDA, Heloísa Buarque de (org.). Pós-modernismo e Política. Rio de Janeiro: Rocco, 1991. p. 15-47.

INFANTE, Cuillermo Cabrera. "Para entender a David Lynch Un Faulkner para los '90". In: Primer Plano. 06/10/1991.

JAMESON, Fredric. Pós-modemismo: a lógica cultural do capitalismo tardio. Trad. de Maria Elisa Cevasco. São Paulo: Ática, 1991.

As marcas do visível. Trad. de Ana Lúcia de Almeida Gazolla, João Roberto Martins Filho, Klauss Brandini Gerhardt, et al. Rio de Janeiro: Graal, 1995.

KAEL, Pauline. 1001 noites no cinema. Seleção de Sérgio Augusto. Trad. de Marcos Santarrita e Alda Porto. São Paulo: Companhia das Letras, 1994.

KAYSER, Wolfgang. O grotesco. Trad. de J. Guinsburg. São Paulo: Perspectiva, 1986.

LYNCH, David. Lynch on Lynch. Edited by Chris Rodley. London: Faber and Faber, 1997. . Images. New York: Hyperion, 1994.

LYNCH, David \& GIFFORD, Barry. Lost Highway. Londres: Faber and Faber, 1997. 
NOLASCO, Sonia. "Cinema moderno rouba as tintas de Hopper". In: O Estado de S. Paulo. São Paulo, 20/07/1995.

RENNER, Rolf Günter. Edward Hopper. Trad. de Casa das Línguas. Benedikt Taschen, 1992.

SADE, Marquis de. A filosofia na alcova, ou, Os preceptores imorais: diálogos destinados a educação das mocinhas / Marquês de Sade. Apresentação de Eliane Robert Moraes. Salvador: Agalma, 1995.

XAVIER, Ismail. $O$ discurso cinematográfico: a opacidade e a transparência. 2.ed. Rio de Janeiro: Paz e Terra, 1984.

Palavras -chave

1. David Lynch

2. análise filmíca

3. cinema limitrofe

4. cinema ilusionista/antiilusionista

5. traços autorais 